\title{
Overcoming Barriers to Experimentation in Business-to-Business Living Labs
}

\author{
Ruben D'Hauwers, Aron-Levi Herregodts, Annabel Georges, \\ Lynn Coorevits, Dimitri Schuurman, Olivier Rits, and Pieter Ballon
}

\author{
(' There are three principal means of acquiring knowledge: ") \\ observation of nature, reflection, and experimentation. \\ Observation collects facts; reflection combines them; \\ experimentation verifies the result of that combination.
}

Denis Diderot (1713-1784)

Philosopher, art critic, and writer

\begin{abstract}
Business-to-business (B2B) living lab projects have been mentioned in different areas of academic research, but the innovation management literature requires deeper analysis of their potential opportunities and challenges. Real-life experimentation is a key requirement for living labs as it enables deeper insights in the potential success of innovations. However, the literature has not provided insights on how living lab projects can implement real-life experimentation in B2B innovation projects and does not describe appropriate conditions for experimentation in these settings. In this study, we identified three main barriers preventing real-life experimentation in B2B living lab projects: the technological complexity, the need for integration, and the difficulty in identifying testers. The barriers are discussed in detailed and potential solutions are provided to help overcome these barriers and stimulate the adoption of real-life experimentation in B2B innovation projects.
\end{abstract}

\section{Introduction}

Providers of "living labs as a service" - who offer services such as designing the idea-generation processes, planning or carrying out real-world tests of innovations, and assessing pre-market launches (Ståhlbröst, 2013) are confronted with an ever-increasing demand for B2Boriented projects. $\mathrm{B} 2 \mathrm{~B}$ companies focus on transactions between companies, whereas business-to-consumer (B2C) companies sell their products directly to the end user (Chauhan \& Anbalagan, 2014). Both B2B and B2C innovation projects are confronted with a range of uncertainties throughout their development process, but much of the focus of the living lab literature has been on $\mathrm{B} 2 \mathrm{C}$ projects.

In this article, we draw upon experiences dating back to 2005 with the establishment of iLab.o, the predecessor of iMinds Living Labs, which is now imec.livinglabs (imec-int.com/en/livinglabs). The organization's first pro- jects were situated in a B2C context (see Schuurman [2015] for a detailed historical overview). However, as iLab.o evolved into a living-lab-as-a-service offering and started to attract more and more utilizers, we witnessed an inflow of B2B projects (see Schuurman et al. [2016] for an overview of the projects). While putting the proof-tested methods used by open innovation research in $\mathrm{B} 2 \mathrm{C}$ projects into practice in a $\mathrm{B} 2 \mathrm{~B}$ environment, we discovered that the application of real-life experimentation in B2B-oriented living lab projects poses particular methodological as well as practical challenges. Given that real-life testing with potential users of the innovation is one of the main characteristics of living labs, and the literature on B2B living lab projects is scant, we aim to contribute to the academic literature by analyzing opportunities for real-life testing in eight case studies of B2B living labs. Through a cross-case analysis, we identify the main barriers to B2B experimentation and their respective potential solutions. 


\title{
Overcoming Barriers to Experimentation in Business-to-Business Living Labs
}

\author{
R. D'Hauwers, A.-L. Herregodts, A. Georges, L. Coorevits, D. Schuurman, O. Rits, and P. Ballon
}

\section{Living Labs and Real-Life Experimentation}

In the context of living labs, the innovation process has evolved from a single-inventor perspective towards a collaborative development of two or more actors. In these collaborative efforts, the crucial role of co-creation has to be emphasized (Bogers et al., 2010; Schuurman et al., 2015). As Schuurman (2015) describes, a living lab is "a tool for distributed innovation that drives co-creation between the different actors involved, while providing the user with a central role". Indeed, organizations want to utilize co-creation in order to tap into the knowledge of (end) users (Kristensson et al., 2008).

Følstad (2008) argues that, in order for users to provide valuable contributions to the innovation at hand, they need to be able to experiment with the innovation and ideally do so in a real-life context. Real-life experimentation is seen as a defining characteristic of living labs (Schuurman, 2015). Coorevits and Schuurman (2015) argue that innovation is unpredictable because of contextual factors, influencing the product usage during this real-life experimentation (Sein et al., 2011) and therefore the testing of products built in the front-end of design is crucial. Forlizzi and Ford (2000) also stress the importance of the context-of-use, which influences the interaction of the user with the innovation. Therefore, it is of utmost importance to provide users with ample opportunities to experiment with the innovation, at least in a familiar and preferably real-life context. It is here that living labs are different compared to other innovation methods (Niitamo et al., 2006; Schuurman \& De Marez, 2012; Coorevits, 2015). Testing not only provides context-specific insights on the development and acceptance of the innovation, but also informs researchers and practitioners about the conditions of technology acceptance and the impact of the innovation on the society and on its environment (Frissen \& Van Lieshout, 2004).

\section{Towards B2B (B2B) Living Labs}

Since 2009, imec.livinglabs (formerly known as iLab.o and iMinds Living Labs) has offered "living labs as a service" to reach its mission of facilitating digital innovation in Flanders, Belgium. The service offering of the imec.livinglabs is focused on confronting potential end users with innovations by small and medium-sized enterprises (SMEs) through co-creation and real-life experimentation. In order to succeed in this facilitation, a key asset of the imec.livinglabs organization is its B2C-focused panel of potential test users. The majority of these projects are based on bilateral agreements, with a project usually lasting three to six months. Table 1 shows
Table 1. Increasing proportion of B2B living lab cases at imec.livinglabs from 2009 to 2016

\begin{tabular}{lcccc}
\hline & B2B & B2C & Total & \% B2B \\
\hline $\begin{array}{l}\text { First 5 years } \\
(2009-2014)\end{array}$ & 4 & 18 & 22 & $18 \%$ \\
\hline $\begin{array}{l}\text { Next 2 Years } \\
(2014-2016)\end{array}$ & 21 & 19 & 40 & $53 \%$ \\
\hline $\begin{array}{l}\text { Overall } \\
(2009-2016)\end{array}$ & $\mathbf{2 5}$ & $\mathbf{3 7}$ & $\mathbf{6 2}$ & $\mathbf{4 0 \%}$ \\
\hline
\end{tabular}

the recent increase of $\mathrm{B} 2 \mathrm{~B}$ projects relative to $\mathrm{B} 2 \mathrm{C}$ projects in the portfolio of the imec.livinglabs. Over the course of the organization's first five years (2009-2014), B2B projects accounted for less than $20 \%$ of all cases. Many innovations of SMEs in Flanders are in the B2B market, and while these innovations previously did not take into account the needs of business users, a shift in the market could be observed. imec.livinglabs reacted to this evolution by integrating business model expertise into its offering (see Rits et al., 2015). The positioning of living labs in the $\mathrm{B} 2 \mathrm{~B}$ market of imec.livinglabs proved successful as evidenced by the absolute increase in B2B projects and the shift in the proportion of $\mathrm{B} 2 \mathrm{~B}$ projects where more than half of recent projects were $\mathrm{B} 2 \mathrm{~B}$ oriented.

This shift from B2C-oriented projects to B2B-oriented projects is important to investigate because of the different characteristics and needs of these two settings. In general, compared to B2C markets, B2B markets have a limited number of customers that generate the largest part of the revenue (Sheth et al., 2000). Thus, when compared to $\mathrm{B} 2 \mathrm{C}, \mathrm{B} 2 \mathrm{~B}$ transaction values tend to be larger and purchase cycles tend to be longer (Brennan et al., 2007; Griffin, 2001). Also, the markets feature different methods of interaction between the business and the client, with B2B traditionally favouring face-to-face interactions (Di Fiore, 2016). Thus, in new product development, a relatively small set of potential B2B customers can exert significant influence over a firm's innovation (Bonner \& Walker, 2004). Moreover, the decision makers might not be the actual users of the innovation, which impact the open innovation process significantly. Given that top managers may play a crucial role in driving innovations (Tellis et al., 2009) and may determine the direction of the innovation, a different role needs to be attributed to different types of users. Abrell and colleagues (2016) argue that customers making the purchasing decisions can provide knowledge about 


\title{
Overcoming Barriers to Experimentation in Business-to-Business Living Labs
}

\author{
R. D'Hauwers, A.-L. Herregodts, A. Georges, L. Coorevits, D. Schuurman, O. Rits, and P. Ballon
}

short-term changes in market needs, whereas users working directly with the products provide long-term guidance for digital innovation. Looking at innovation, Castro (2015) states that B2B firms focus on internal processes and capabilities and product-mix innovations, whereas B2C firms innovate on the brand, presence, and customer experience. This difference affects which methodologies can be applied in this context. The application of real-life experimentation in B2B-oriented living lab projects poses methodological as well as practical challenges and implications for organizations offering living labs as a service, which have not been explored in the living lab literature.

The academic importance attributed to real-life testing and experimentation reinforces the need to assess such an approach in B2B-oriented living-labs-as-a-service projects. Although some authors (Ballon et al., 2005; Almirall et al., 2012) explicitly mention B2B living labs, no clear insights are provided on the application of reallife experimentation in these distinctive environments. Ballon and colleagues (2005), for example, make note of considerable differences in experimenting with innovations between $\mathrm{B} 2 \mathrm{~B}$ and $\mathrm{B} 2 \mathrm{C}$ test and experimentation platforms (TEPs). However, they offer no guidelines on this matter. Further, Almirall, Lee, and Wareham (2012) report that most cases in the Catalan Living Labs are B2B projects. They also compare the general methodological approaches of four living lab intermediaries in terms of the act of user involvement, the interpretation of real-life contexts, and the public-private-partnerships. However, the specific methodological differences between B2C and B2B contexts are not discussed, nor are any guidelines provided in relation to that distinction.

\section{Case Study: Eight B2B Living Labs}

We used an exploratory action research approach (Davison et al., 2004). We selected eight cases that were executed by imec.livinglabs as part of their living lab as a service, which is tailored towards SMEs. To ensure reliability, relevance, and comparability, the cases were selected according following criteria: i) the living lab projects had to be completely finished, ii) the cases must have been carried out between 2012 and 2016, and iii) the cases must be of a B2B nature. A case study approach was selected due to the absence of a clear supporting theory (on B2B living labs) and the exploratory nature of the study, in which key variables and their relationship are under investigation (Eisenhardt, 1989; Yin, 2009).

We defined a five-point scale (Table 2) to measure the extent of user involvement in a B2B living lab context.
We followed Følstad (2008) to differentiate between a familiar, semi-real context (Level 3) and a real-life context (Level 4). We defined Level 3 as testing without interacting with the entire ecosystem the product usually would operate in and it is thus not integrated with other processes. The familiar context can serve as an alternative to the real world by allowing greater balance between the threat of low ecological validity related to test labs and the uncontrollable aspect of field studies. In B2B environments, a familiar context might be a pilot or prototype environment wherein the real-life context is simulated as much as possible. Researchers often opt for the familiar context so they can maintain control over a selection of elements they want to investigate, such as pre-defined task execution to determine the learnability of an application.

The testing in Level 4 goes one step further: users interact with the innovation in a real-life setting. The entire ecosystem is involved and integration is included as well. In the context of B2C-oriented living labs, (end)users are confronted with technology in their everyday lives. In this situation, researchers cannot control the users' actions and the external elements influencing their behaviour. The real-life aspect of the test environment should provide the researcher with "unexpected" outcomes to improve the innovation (Sauer, 2013). As described by Almirall and colleagues (2012), "Real-life contexts are much more than a more realistic scenario for validating proposals; they form an arena where new meanings can emerge, tacit knowledge can be captured, and the whole ecosystem can be validated."

Table 2. Five levels of user involvement in a B2Boriented living lab

\begin{tabular}{cl}
\hline Level & Extent of User Involvement \\
\hline 0 & No user involvement \\
\hline 1 & $\begin{array}{l}\text { Users describe their needs in an } \\
\text { exploratory manner }\end{array}$ \\
\hline 2 & $\begin{array}{l}\text { Users provide feedback after observing an } \\
\text { innovation but do not interact with it }\end{array}$ \\
\hline 3 & $\begin{array}{l}\text { Users test an innovation in a familiar, } \\
\text { semi-real context }\end{array}$ \\
\hline 4 & $\begin{array}{l}\text { Users test an innovation in their real-life } \\
\text { context }\end{array}$ \\
\hline
\end{tabular}




\title{
Overcoming Barriers to Experimentation in Business-to-Business Living Labs
}

\author{
R. D'Hauwers, A.-L. Herregodts, A. Georges, L. Coorevits, D. Schuurman, O. Rits, and P. Ballon
}

Table 3 summarizes our eight B2B living lab cases, five of which featured real-life testing (Level 4) and one of which featured testing in a familiar environment (Level $3)$. Table 3 also indicates that, in four of the cases, a real-life test was not performed within the scope of the actual imec.livinglabs project. In these cases, the entrepreneur performed the real-life testing on their own. Here, the role of imec.livinglabs was limited to identifying potential testing cases and coaching the entrepreneur on the execution of the real-life test, and potentially also assisting with the analysis of the results.

Through a cross-case study, we identified three main B2B-specific barriers to real-life testing - process integration, technological complexity, and tester identification - as shown in Figure 1. Each barrier is described in greater detail in the subsections that follow, along with proposed solutions for overcoming these barriers.

\section{Barrier 1: Process integration}

When setting up a field study (e.g., in cases 4, 6, and 8), integration was required between the innovation and the existing processes in the companies. If integration is required, the company needs to make a larger commitment to adapt existing processes in the firm, and the IT department of the company will need to be included in the project, which leads to higher project

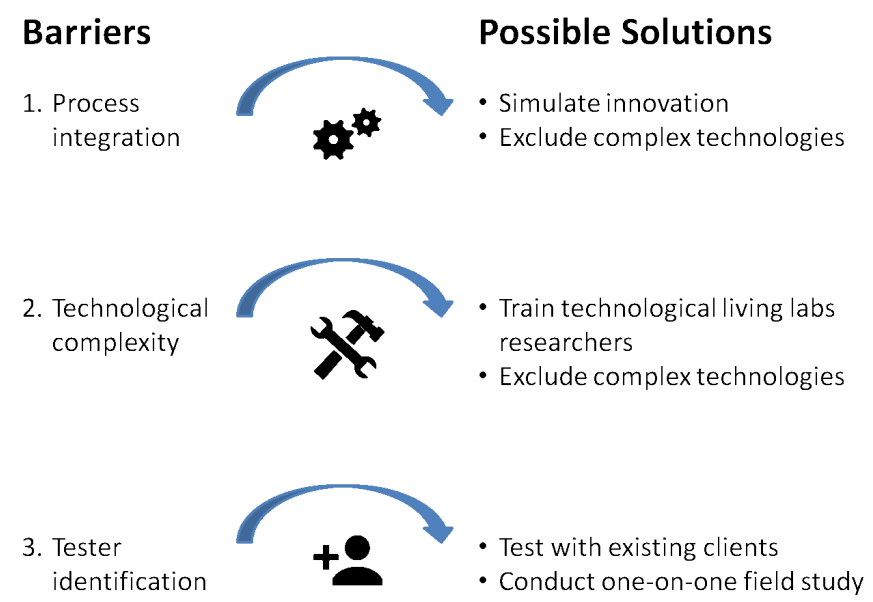

Figure 1. Three barriers to experimentation in B2B living labs and possible solutions

complexity. Nevertheless, in case 4, a proxy technology assessment was set up to simulate the technology through an alternative, simpler solution that could circumvent the difficult integration with existing procedures. A proxy technology assessment takes into account the context influencing the interaction of the user with the innovation in the front end of design and thus can provide an alternative to a field study early in the innovation process (Coorevits \& Schuurman, 2015).

Table 3. Descriptions of the assessed cases of B2B living labs, their extent of user involvement, and the main testing entity

\begin{tabular}{clll}
\hline Case & Case Description & $\begin{array}{c}\text { Extent of User } \\
\text { Involvement }\end{array}$ & Testing Entity \\
\hline 1 & A technology aiming to improve case management of processes in companies & Level 4 & Entrepreneur \\
\hline 2 & A startup focused on digital signage of content applications & Level 4 & Entrepreneur \\
\hline 3 & $\begin{array}{l}\text { Improving the sourcing process by improving the information exchange between } \\
\text { requestors, collaborators, and buyers }\end{array}$ & Level 4 & imec.livinglabs \\
\hline 4 & Coaching managers and employees on change & Level 3 & imec.livinglabs \\
\hline 5 & A solution to build, share, and manage knowledge in companies & Level 0 & None \\
\hline 6 & $\begin{array}{l}\text { An Internet of Things (IoT) platform in a B2B context enabling companies to } \\
\text { prototype loT solutions }\end{array}$ & Level 4 & Entrepreneur \\
\hline 7 & A solution to track goods in the circular economy & Level 0 & None \\
\hline 8 & An integration layer for issue-tracking software & Level 4 & Entrepreneur \\
\hline
\end{tabular}




\title{
Overcoming Barriers to Experimentation in Business-to-Business Living Labs
}

\author{
R. D'Hauwers, A.-L. Herregodts, A. Georges, L. Coorevits, D. Schuurman, O. Rits, and P. Ballon
}

In cases where real-life testing proves to be difficult due integration with other processes, we argue that simulations of the innovation, such as proxy technology assessments, can help overcome this barrier to experimentation.

\section{Barrier 2: Technological complexity}

In cases 6 and 8 , the technology was highly complex, as the target market involved IT professionals in different organizations. The user researchers did not have a deep background or expertise on these innovations, which made it difficult to understand the technical needs of the users. For that reason, it was too difficult to test the concept in a field study because the user researchers would encounter difficulties in being the translator between the designer and user. The complexity in both cases was linked to the need for integration, thus the barrier of technological complexity and the barrier of process integration (possibly) go hand in hand, but this aspect needs further research.

We argue that, to overcome the barrier to technological complexity, complicated technologies should either be excluded from testing in from B2B living labs or technical experts should be trained to perform experimentation in technologically complicated environments.

\section{Barrier 3: Tester identification}

The identification and selection of testers proved to be challenging in cases 3 and 6 , and it prevented the inclusion of field studies in those projects. The difficulties in identifying B2B testers arose due to a smaller pool of potential testers. Thus, the recruitment of testers may be more resource intensive in $\mathrm{B} 2 \mathrm{~B}$ projects than in $\mathrm{B} 2 \mathrm{C}$ projects.

This barrier can be overcome by utilizing existing clients of the entrepreneur, which might make the process of identifying testing entities more efficient. A living lab project can also be a starting point for another research project focusing on the field study in a oneon-one relationship between two research partners (the entrepreneur and their potential client), as was the shown in case 6. Alternatively, the living lab can coach the entrepreneur to perform the field study themselves.

\section{Conclusion}

In this study, we identified and proposed solutions to three specific barriers hindering experimentation in B2B living labs: i) process integration between the existing company processes and the innovation, ii) technological complexity of the innovation, and iii) limitations on the identification and selection of relevant testers. These identified barriers require careful consideration and operationalization of living labs in the context of B2B projects.

Next to overcoming these three barriers, we can first try to avoid them with a more rigid selection of $\mathrm{B} 2 \mathrm{~B}$ projects that are suitable for living labs. A living lab could, for example, solely accept B2B projects with ready-to-test user interfaces and exclude $\mathrm{B} 2 \mathrm{~B}$ projects focused on process integration. This living lab self-criticism on the potential of methodologies and formats for B2B projects deserves its own discussion.

Another avenue for further exploration is to identify a positioning of the living labs in cases where real-life tests are performed by the entrepreneurs themselves. The entrepreneur potentially lacks the expertise and experience to perform a real-life test and might not focus on the user aspects of the innovation. Therefore, the providers of living-labs-as-a-service can position themselves as coaches rather than actual implementers of the real-life tests.

Potentially, living labs can also explore the potential of a B2B-focused panel similar to the B2C panel utilized by imec.livinglabs. This approach would potentially improve the identification and selection of testers for $\mathrm{B} 2 \mathrm{~B}$ innovations.

In conclusion, we believe that overcoming the identified contextual barriers through the different solutions we proposed - and others to be identified in future research - real-life experimentation in B2B living labs can prove to be highly beneficial to the development of $\mathrm{B} 2 \mathrm{~B}$ innovations. 


\title{
Overcoming Barriers to Experimentation in Business-to-Business Living Labs
}

\author{
R. D'Hauwers, A.-L. Herregodts, A. Georges, L. Coorevits, D. Schuurman, O. Rits, and P. Ballon
}

\section{About the Authors}

Ruben D'Hauwers is a Researcher at imec - SMIT VUB in Belgium. He holds a master's degrees in Business Engineering (2011) and Innovation and Entrepreneurship (2013). He has also worked in the field of business development in two different organizations. He joined imec in 2014 and focuses on business-tobusiness research, business modelling, and on capturing and validating the assumptions throughout the innovation process.

Aron-Levi Herregodts is a User Expert at imec.livinglabs and an affiliated researcher at imec - MICT Ghent University in Belgium. He holds master's degrees in Communication Sciences (2013) and Complementary Business Economics (2014). As a user expert, his role is to translate user behaviour, needs, and wants into tangible recommendations to provide structure to the innovation process of both SMEs and large organizations. His main research interests include open innovation, user innovation, organizational learning, intermediary activities, and user-centric design and methodologies. $\mathrm{He}$ is also preparing a $\mathrm{PhD}$ on the configuration of intermediary user-oriented activities with innovation-relevant actors for distinct types of entrepreneurs and innovations.

Annabel Georges is a Junior Researcher in the research group at imec - MICT - Ghent University in Belgium. She holds a master's degree in Communication Sciences from Ghent University, with a specialization in New Media and Society. Her main interests are domestication theory, field tests, and improvements to living lab practices.

Lynn Coorevits is a Senior User Researcher for imecMICT - Ghent University in Belgium, where she focuses on tools and techniques for open and user innovation, such as sensors and design thinking. Her current research focuses on the adoption and attrition of wearables as well as optimization of context integration in living lab projects. She works on several SME living lab projects ranging from the financial to social industry. She holds master's degrees in Psychology and in Marketing Analysis from Ghent University and has 9 years of experience in innovation research and consultancy.
Dimitri Schuurman is the Team Lead in User Research at imec.livinglabs and a Senior Researcher at imec - MICT - Ghent University in Belgium. He holds a $\mathrm{PhD}$ and a Master's degree in Communication Sciences from Ghent University. Together with his imec colleagues, Dimitri developed a specific living lab offering targeted at entrepreneurs in which he has managed over 100 innovation projects. Dimitri is responsible for the methodology and academic valorization of these living lab projects and coordinates a dynamic team of living lab researchers. His main interests and research topics are situated in the domains of open innovation, user innovation, and innovation management. His $\mathrm{PhD}$ thesis was entitled Bridging the Gap between Open and User Innovation? Exploring the Value of Living Labs as a Means to Structure User Contribution and Manage Distributed Innovation.

Olivier Rits holds a master's degree in Applied Physics (Engineering) from the Ghent University in Belgium. Previously, Olivier worked as a business developer for Alcatel-Lucent, where he was involved with many different technologies. Within SMIT, Olivier is leading the business modelling practice in the context of SME living lab innovation projects. With a team of researchers, he is organizing business model workshops and stakeholder interviews to apply business model methodologies to link the user feedback and insights to the business model aspects of the SME's strategy. Olivier is also involved in business modelling efforts in research projects dealing with ICT in general, with a specific interest in M2M and IoT and mobile telecommunications.

Pieter Ballon is the Academic Lead of imec.livinglabs, the International Secretary of the European Network of Living Labs, and Director of the research group imec-SMIT at Vrije Universiteit Brussel in Belgium. He specializes in business modelling, open innovation, and the mobile telecommunications industry. Formerly, he was Senior Consultant and Team Leader at TNO. From 2006-2007, he was the coordinator of the cross issue on business models of the Wireless World Initiative (WWI), which united five integrated projects in the European Union's 6th Framework Programme. Pieter holds a PhD in Communication Sciences from Vrije Universiteit Brussel and an MA in Modern History from Katholieke Universiteit Leuven. 


\title{
Overcoming Barriers to Experimentation in Business-to-Business Living Labs
}

\author{
R. D'Hauwers, A.-L. Herregodts, A. Georges, L. Coorevits, D. Schuurman, O. Rits, and P. Ballon
}

\section{References}

Abrell, T., Pihlajamaa, M., Kanto, L., vom Brocke, J., \& Uebernickel, F. 2016. The Role of Users and Customers in Digital Innovation: Insights from B2B Manufacturing Firms. Information \& Management, 53(3): 324-335.

http://dx.doi.org/10.1016/j.im.2015.12.005

Almirall, E., Lee, M., \& Wareham, J. 2012. Mapping Living Labs in the Landscape of Innovation Methodologies. Technology Innovation Management Review, 2(9): 12.

Ballon, P., Pierson, J., \& Delaere, S. 2005. Test and Experimentation Platforms for Broadband Innovation: Examining European Practice. Paper presented at the 16th European Regional Conference by the International Telecommunications Society, September 4-6 Porto, Portugal,.

Bogers, M., Afuah, A., \& Bastian, B. 2010. Users as Innovators: A Review, Critique, and Future Research Directions. Journal of Management, 36(4): 857-875. http://dx.doi.org/10.1177/0149206309353944

Bonner, J. M., \& Walker, O. C. 2004. Selecting Influential Business-toBusiness Customers in New Product Development: Relational Embeddedness and Knowledge Heterogeneity Considerations. Journal of Product Innovation Management, 21(3): 155-169. http://dx.doi.org/10.1111/j.0737-6782.2004.00067.x

Castro, V. 2015. Innovation Importance Across Dimensions for Business-to-Business and Business-to-Consumer Firms: A Case Study-Based Analysis. Wharton Research Scholars, 132. http://repository.upenn.edu/wharton_research_scholars/132/

Coorevits, L., \& Schuurman, D. 2015. Increasing Relevance of Living Lab Outcomes through Proxy Technology Assessments. Paper presented at the Open and User Innovation Conference, July 13-15, Lisbon, Portugal.

Davison, R., Martinsons, M. G., \& Kock, N. 2004. Principles of Canonical Action Research. Information Systems Journal, 14(1): 65-86.

http://dx.doi.org/10.1111/j.1365-2575.2004.00162.x

Eisenhardt, K. M. 1989. Building Theories from Case Study Research. Academy of Management Review, 14(4): 532-550. http://dx.doi.org/10.5465/AMR.1989.4308385

Følstad, A. 2008. Living Labs for Innovation and Development of Information and Communication Technology: A Literature Review. eJOV: The Electronic Journal for Virtual Organizations, 10: 99-131.

Forlizzi, J., \& Ford, S. 2000. The Building Blocks of Experience: An Early Framework for Interaction Designers. In Proceedings of the 3rd Conference on Designing Designing Interactive Systems: 419-423. New York: ACM.

http://dx.doi.org/10.1145/347642.347800

Frissen, V., \& van Lieshout, M. 2004. To User-Centred Innovation Processes: The Role of Living Labs. Delft, Netherlands: TNO-ICT.
Griffin A. 2001. Product Development Cycle Time for B2B Products. Industrial Marketing Management, 31(4): 291-304. http://dx.doi.org/10.1016/S0019-8501(01)00162-6

Kristensson, P., Matthing, J., \& Johansson, N. 2008. Key Strategies for the Successful Involvement of Customers in the Co-Creation of New Technology-Based Services. International Journal of Service Industry Management, 19(4): 474-491. http://dx.doi.org/10.1108/09564230810891914

Niitamo, V., Kulkki, S., Eriksson, M., \& Hribernik, K. A. 2006. State-ofthe-Art and Good Practice in the Field of Living Labs. In Proceedings of the 12th International Conference on Concurrent Enterprising: Innovative Products and Services through Collaborative Networks: 341-348. Milan: IEEE. http://dx.doi.org/10.1109/ICE.2006.7477081

Rits, O., Schuurman, D., \& Ballon, P. 2015. Exploring the Benefits of Integrating Business Model Research within Living Lab Projects. Technology Innovation Management Review, 5(12): 19-27. http://timreview.ca/article/949

Sauer, S. C. 2013. User Innovativeness in Living Laboratories: Everyday User Improvisations with ICTs as a Source of Innovation. Thesis No. 13-256. Enschede, Netherlands: University of Twente.

Schuurman, D., \& De Marez, L. 2012. Structuring User Involvement in Panel-Based Living Labs. Technology Innovation Management Review, 2(9): 31-38.

http://timreview.ca/article/606

Schuurman, D. 2015. Bridging the Gap between Open and User Innovation? Exploring the Value of Living Labs as a Means to Structure User Contribution and Manage Distributed Innovation. Doctoral dissertation. Ghent University and Vrije Universiteit Brussel VUB.

Schuurman, D., De Marez, L., \& Ballon, P. 2016. The Impact of Living Lab Methodology on Open Innovation Contributions and Outcomes. Technology Innovation Management Review, 1(6): 7-16. http://timreview.ca/article/956

Sein, M. K., Henfridsson, O., Rossi, M., \& Lindgren, R. 2011. Action Design Research. MIS Quarterly, 35(1): 37-56.

Sheth, J. N., Sisodia, R. S., \& Sharma, A. 2000. The Antecedents and Consequences of Customer-Centric Marketing. Journal of the Academy of Marketing Science, 28(1): 55-66. http://dx.doi.org/10.1177/0092070300281006

Ståhlbröst, A. 2013. A Living Lab as a Service: Creating Value for Micro-Enterprises through Collaboration and Innovation. Technology Innovation Management Review, 3(11): 37-42. http://timreview.ca/article/744

Tellis, G. J., Prabhu, J. C., \& Chandy, R. K. 2009. Radical Innovation across Nations: The Preeminence of Corporate Culture. Journal of Marketing, 73(1): 3-23.

http://dx.doi.org/10.1509/jmkg.73.1.3

Yin, R. K. 2009. Case Study Research: Design and Methods. Thousand Oaks, California: SAGE Publications, Inc. 